\title{
A study on the use of disposable products in hotels based on low carbon consumption
}

\author{
Kejiang Chen ${ }^{1, *}$, Tairan Huang ${ }^{1}$, Yichen Zhang ${ }^{1}$, and Zimu Zhu ${ }^{1}$ \\ ${ }^{1}$ HNU-ASU Joint International Tourism College, Hainan Universit, Haikou, China
}

\begin{abstract}
In recent years, the world has been committed to the development of environmental industries and sustainable resources, and continues to implement the strategic idea of the scientific concept of development to prevent environmental pollution and resource waste. However, the nation seems to be accustomed to the use of disposable items such as toothbrushes, toothpaste and slippers in hotels. With the rapid development of the hotel industry, a large number of disposable items have been used in the hotel industry for a long time, which has brought great pressure to the environment and does not meet the requirements of the concept of low-carbon economy and green development. Through the investigation and analysis of the use of disposable products in hotels, this paper explores the solution and feasibility of banning disposable products in hotels, aiming to contribute to the low carbon economy and low carbon consumption.
\end{abstract}

\section{Introduction}

The hotel is like a temporary home for guests, it provides services to meet the needs of guests staying overnight, including the supply of various daily necessities, such as disposable toothbrushes, toothpaste, soap, bath soap, slippers, combs and other "six small items", and some hotels even provide free disposable razors or women's cosmetics. These items are consumed in large quantities by different guests every day. Although some supplies such as razors are not all disposable and ready to use, but because they are personal items, hotels do not reuse them for hygiene and customer psychological considerations, so guests enjoy the convenience of the hotel while also causing a lot of waste of resources and environmental pollution. This paper analyzes the use of disposable items in hotels and the difficulties in the implementation of current disposal methods, and explores practical ways to deal with them, taking into account the experience of hotel reform in the international community.

\section{The current situation of disposable goods use in China hotels}

The use of disposable hygiene products in hotels often appear "less with more loss" phenomenon, the phenomenon of waste is serious, increasing the cost of the hotel, while cheap disposable supplies is not only a consumption of resources, due to the low price of disposable supplies, there are also many quality problems of their own, affecting the guest experience, and even to human health It will also constitute an impact on human health.

\subsection{Quality}

The following table shows the disposable hygiene products (including paper products, women's sanitary napkins, slippers, shower caps, dental tools, etc.) used in 132 star hotels in a city for supervision and hygienic quality testing [1]. From the hygienic point of view: women's sanitary napkins and beverage straws had the lowest pass rate of $66.67 \%$ [1]. E. coli was detected on some facial tissues and dental instruments, and mold was detected on some napkins, dental instruments, and women's sanitary napkins. Thus, the use of disposable sanitary products leading to disease occurs, and according to the survey most gynecological diseases are caused by the use of unqualified sanitary napkins [1].

Table 1. Hotel disposable hygiene products testing.

\begin{tabular}{|c|c|c|c|}
\hline Name & $\begin{array}{c}\text { Number of } \\
\text { tests/sample }\end{array}$ & $\begin{array}{c}\text { Number of } \\
\text { qualified } \\
\text { copies }\end{array}$ & $\begin{array}{c}\text { Qualification } \\
\text { rate \% }\end{array}$ \\
\hline Paper Category & 188 & 171 & $90.96 \%$ \\
\hline Sanitary napkin & 9 & 7 & $77.78 \%$ \\
\hline $\begin{array}{c}\text { Slippers, shower } \\
\text { caps, combs }\end{array}$ & 215 & 201 & $93.49 \%$ \\
\hline Toothpieces & 137 & 129 & $94.16 \%$ \\
\hline Drink straws & 8 & 6 & $75.00 \%$ \\
\hline Others & 17 & 15 & $88.24 \%$ \\
\hline Total & 517 & 499 & $96.52 \%$ \\
\hline
\end{tabular}

\subsection{Analysis of the use of hotel disposables}

Table 2 shows the monthly breakdown of consumable items, i.e. disposables, in a hotel. It is easy to find that

* Corresponding author: kejiang-up@foxmail.com 
except for paper slippers, shampoo and body soap, there is a large surplus of other items, and there are many disposable items that are discarded before they are used up. These disposable items are generally very cheap, and hotels will buy them in large quantities and place them in the hotel rooms, generally for free use by customers. At the same time, customers lack the concept of reasonable use of disposable supplies, such as combs, shoe shine cloths, small garbage bags, coasters, matches and other non-essential items will have a large balance, each time the cleaning of the room will reset these supplies, resulting in a lot of waste.

In addition, according to Finance.com, more than 70\% of soap in Chinese hotels is discarded after one use, and 440,000 hotels in China discard more than 400,000 tons of soap each year, valued at 8 billion yuan, but soap waste is only the tip of the iceberg of hotel disposable waste [2].

Table 2. Use of disposable supplies.

\begin{tabular}{|c|c|c|c|c|}
\hline Number & Name & $\begin{array}{c}\text { Unit } \\
\text { price/yuan }\end{array}$ & $\begin{array}{c}\text { Consumption } \\
\text { this month/pc }\end{array}$ & Stock/pc \\
\hline 1 & Toothbrush & 0.6 & 6500 & 5500 \\
\hline 2 & Comb & 0.4 & 4000 & 15500 \\
\hline 3 & Soap & 0.3 & 2500 & 1000 \\
\hline 4 & Shower cap & 0.2 & 1500 & 3500 \\
\hline 5 & $\begin{array}{c}\text { Shoe shine } \\
\text { cloth }\end{array}$ & 0.58 & 1500 & 17000 \\
\hline 6 & Toilet paper & 0.95 & 1020 & 1740 \\
\hline 7 & Mineral water & 0.47 & 7950 & 4455 \\
\hline 8 & Paper towels & 2.13 & 120 & 152 \\
\hline 9 & $\begin{array}{c}\text { Large garbage } \\
\text { bag }\end{array}$ & 0.08 & 8000 & 38000 \\
\hline 10 & $\begin{array}{c}\text { Small garbage } \\
\text { bag }\end{array}$ & 0.5 & 650 & 200 \\
\hline 11 & Paper slippers & 0.68 & 4000 & 0 \\
\hline 12 & $\begin{array}{c}\text { Cotton } \\
\text { slippers }\end{array}$ & 1.2 & 0 & 500 \\
\hline 13 & Shampoo & 36 & 11 & 3 \\
\hline 14 & Shower cap & 36 & 14 & 6 \\
\hline 15 & Small pencils & 0.15 & 100 & 100 \\
\hline 16 & Coaster & 0.1 & 300 & 31310 \\
\hline 17 & Matches & 0.25 & 250 & 7200 \\
\hline
\end{tabular}

\subsection{Cost issues}

As an example, the following table shows that some hotels are using more disposable hygiene products than they should [3]. From a cost perspective: If there are 1,000 rooms with $50 \%$ occupancy and a set of disposable items for one room is calculated at $\$ 20$, the hotel will consume about $\$ 10,000$ per day for "six small items" [3]. Over the course of a year, the hotel would save $\$ 3$ million on just six items [3]. From a green perspective, there are even more benefits than harms. On the one hand, the production of disposable items consumes huge raw materials, and environmental researchers have done statistics that it takes 10,000 trees to cut down 500,000 combs and 20,000 trees to produce 1 million pairs of slippers; on the other hand, the problem of waste disposal of disposable items is also quite serious [3]. The waste rate of "six small items" is up to $70 \%$ or more, and most of them are hard to degrade plastic products, for example, one million garbage bags need 1000 years to degrade, which causes immeasurable pollution to the environment [3].

Table 3. Room disposables consumption.

\begin{tabular}{|c|c|c|c|c|c|}
\hline Name & Unit & $\begin{array}{c}\text { Net } \\
\text { content }\end{array}$ & $\begin{array}{c}\text { Unit } \\
\text { Price }\end{array}$ & $\begin{array}{c}\text { Per capita } \\
\text { consumption }\end{array}$ & $\begin{array}{c}\text { Waste } \\
\text { amount }\end{array}$ \\
\hline Body Wash & Bottle & $40 \mathrm{~g}$ & 1.1 & 0.5 & 1190 \\
\hline Shampoo & Bottles & $40 \mathrm{~g}$ & 1.1 & 0.5 & 1120 \\
\hline Body lotion & Bottle & $40 \mathrm{~g}$ & 1.4 & 0.3 & 1370 \\
\hline 40g soap & Bottle & $40 \mathrm{~g}$ & 0.8 & 0.2 & 1490 \\
\hline Toothpaste & Bottle & $40 \mathrm{~g}$ & 0.6 & 0.5 & 770 \\
\hline Total & & & & & 5940 \\
\hline
\end{tabular}

\subsection{Environmental pollution of primary supplies}

In addition to the economic cost to hotels and the consumption of social resources, as well as the quality of the disposable products themselves, disposable products can cause serious pollution to the environment. Every year, a huge amount of laundry products are wasted in rivers, oceans and soil, causing huge pollution to the environment. That's just the toiletries themselves, not including packaging and other disposable room items, etc., and are also made of plastic, cotton, paper or wood.

Plastic products can not be directly degraded in their natural state, in addition to recycling, can only be incinerated or landfill disposal, so people "talk about plastic". Plastic as the main material of disposable waste generally take the incineration or landfill disposal, but plastic incineration will form many toxic gases and dust, such as sulfur dioxide, nitrous oxide, PM10, etc., if improperly handled will cause serious air pollution, and to save costs, hotel disposables are rarely made of biodegradable materials, 1 million garbage bags need 1000 years to degrade. This leads to intergenerational soil contamination after landfills [3]. As for wood, when forests, the lungs of the earth, are cut down by the axe of man, we should not only call for the rational use and conservation of natural resources, but also for the protection of the ecological environment on which we depend for our survival.

\section{Analysis on the difficulties of hotel reform}

\subsection{Customer needs analysis}

As shown in the figure below, respondents have different demands for "small disposable items" in hotels, which can be arranged in descending order as "slippers $>$ soap $>$ soap $>$ shampoo $>$ shower gel $>$ disposable toothpaste $>$ comb $>$ shower cap" [4]. All respondents needed slippers, which were considered inconvenient to carry; soap demanded up to $90 \%$; shampoo demanded up to $80 \%$; body wash demanded up to $77 \%$; and demand for disposable dental tools was $57 \%$. The demand for combs 
is $47 \%$. The demand for shower cap is not so high, compared to the demand of $7 \%$. Most of the customers have a high demand for the "small disposable items" section in hotels [4].

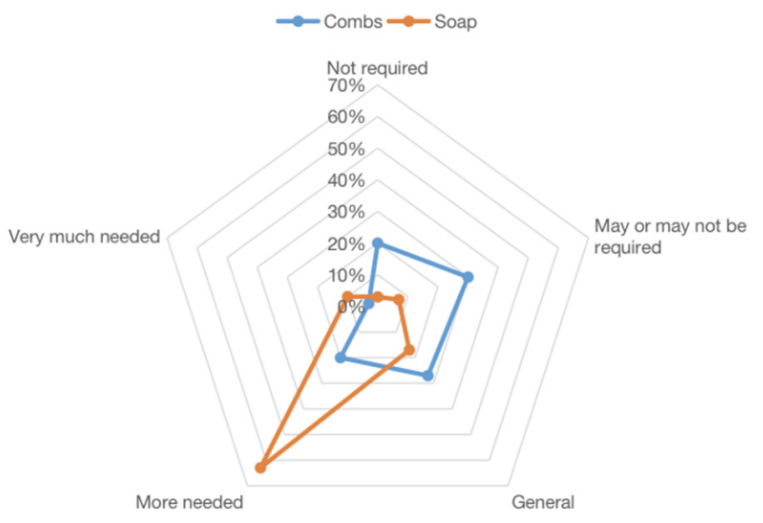

Fig. 1. Demand for combs and soaps.

As can be seen from the figure below, $31 \%$ of customers do not choose to take away hotel disposables, and $47 \%$ choose other options, while only $22 \%$ choose to take away disposables, so at least $70 \%$ of disposables are consumed and may be wasted from the customer's level [1]. And from a survey specifically for tourists, it is known that $63.2 \%$ of tourists use disposable items provided by hotels, and of these $63.2 \%$ about $52.46 \%$ of tourists think that carrying their own toiletries and other items is troublesome and takes up space in their suitcases [5]. For many guests, free disposable items are even part of the hotel service. If not provided, it would leave a bad impression to the residents that the hotel "service is shrinking". Obviously, there are situations in the country where hotels are unable to quickly discontinue the service of providing disposable items regardless of user demand.

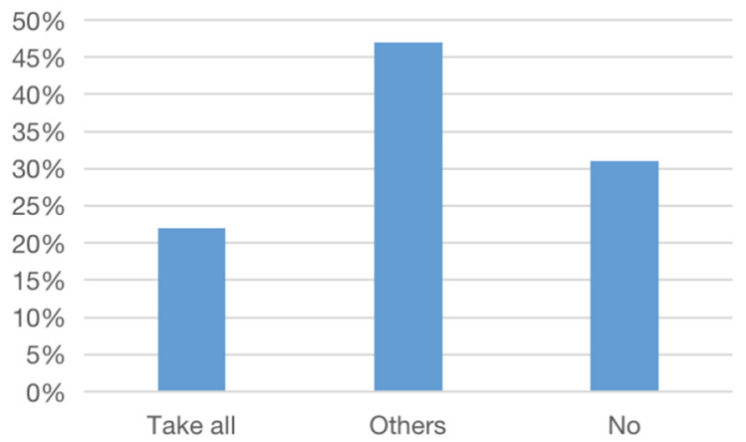

Fig. 2. Use of consumable goods.

\subsection{Analysis of the reasons for the ineffectiveness of measures to limit disposables}

From the previous historical review, we can understand that from nearly two decades ago (2002), various similar measures related to the restriction of disposable products have been implemented in China one after another, but most of them did not achieve the desired effect [6], and there are five main reasons for this.
- Deficiencies in legislation and enforcement. 2011's "Classification and Rating of Tourist Hotel Stars" and 2020's "Opinions on Further Strengthening Plastic Pollution Control" (hereinafter referred to as "Control Opinions"), both published by the National Tourism Administration (NTA), gradually put forward requirements for star-rated hotels to eliminate disposable products [6]. Star-rated hotels serve the middle and high-end customers with the most spending power, from which it can be seen that government policies and decrees still have certain limitations. The government has introduced environmental policies related to disposable goods in hotel rooms, but not with sufficient implementation efforts to implement, resulting in the implementation of regulations in the link is not strict enough, the formation of "ineffective legislation", and finally "no end".

- The lack of environmental awareness. Not all hotel guests, operators and managers have reached a high level of understanding of the concept of environmental protection, especially the construction of "green hotels" [6]. There is not enough awareness of the link between "hotel room disposable reform" and waste reduction and environmental protection.

- Consumers' travel habits. Consumers have not yet formed a green, low-carbon consumption and living habits, the change of habits will be a difficult and slow process. Let stay in the hotel bring their own daily necessities or limit the use of hotel rooms disposable supplies to become a travel fashion, it will take time to test.

- Fierce competition in the hotel industry. "Green Hotel" has not become a competitive advantage of the hotel, for many hotels, for a long time, the hotel in the hardware and service competition is difficult to open up the gap, often using disposable supplies, a lower cost, easy to reflect the characteristics of the details of the service with little input to highlight their differences with the competition, the abolition of Hotel room disposable supplies will instead weaken the hotel's own competitiveness.

- Consumer spending power. For the hotel to cancel or paid use of hotel rooms disposable supplies also need to consider the consumption capacity of different consumer groups, the hotel paid to provide daily supplies service prices should not be too high.

\section{Solutions}

\subsection{Learn from other countries' experience}

To solve this problem at the source, we may want to learn from the experience of South Korea. In order to solve the problem of disposable products in hotels, Korea, on the one hand, raises and maintains national awareness of environmental protection, and on the other hand, introduces mandatory measures to strictly restrict the provision of hotel service products [7]. 2002, Korea conducted a public opinion survey on the restriction of disposable products, and the results showed that more than $90 \%$ of the residents supported restricting the use of disposable products, and $86 \%$ of the citizens said they 
could tolerate the inconvenience of not having disposable $86 \%$ of the people said they could tolerate the inconvenience of not having disposable products. Because of this foundation of national environmental awareness, Korea has only amended the Resource Conservation and Recycling Act to clarify the scope of the definition of disposable items and to set stricter restrictions [7]. The measures include the following.

- Hotels and bathing places are required not to provide free disposable items such as shampoo, toothbrushes, toothpaste, and razors [7].

- Operators must remind customers that they can purchase them from the front desk if needed. In turn, operators must list the amount spent on disposable items separately when invoicing [7].

- Operators fail to comply with the rules, and customers can report and receive rewards [7].

\subsection{Based on national conditions}

It is not feasible for China to directly copy these measures, considering China's national conditions and national consciousness, we should analyze specific problems and learn from foreign experience. The government should promote and advocate to raise consumers' awareness of low-carbon consumption and consumption habits, and include the restriction and elimination of disposable products in the star rating of star hotels. This will not only prevent the re-emergence of free disposable items, but also prevent some hotels from not providing disposable items and then being unwilling to lower their prices to make unreasonable profits. After the conditions are ripe then learn from Japan and the United States to encourage travelers to bring their own supplies and hoteliers to recycle resources.

\subsection{Fit in with national plans and policies to limit the use of primary products in hotels}

On January 19, 2020, China's National Development and Reform Commission and the Ministry of Ecology and Environment jointly issued the "Opinions on Governance", which also mentions the need to be guided by $\mathrm{Xi}$ Jinping's thought of socialism with Chinese characteristics in the new period, adhere to the people as the center, firmly establish a new concept of development, and strive to build a beautiful China. For hotels and hostels, the goal is instead to stop providing single-use plastic products to tourists in star-rated hotels nationwide by the end of 2022 . Instead, the service can only be provided through the installation of self-service purchasing machines and the provision of refillable detergents. And by the end of 2025, the implementation will be extended to all hotels, hostels and boarding houses.

\section{Conclusion}

In a word, hotels should eliminate the use of disposable daily necessities. But fuck actually, this measure is not simple to operate. For a long time, society has been accustomed to hotels providing disposable daily necessities for free. And most Chinese customers have not developed the habit of bringing their own personal items, so many of them rely heavily on the disposable supplies provided by hotels.

In the present time, the development of the hotel industry has been under the attention of the society. Focusing on environmental awareness and achieving sustainable development is an inevitable trend for the future development of the hotel industry. Hotels are a powerful solution by providing paid disposables, but there is still a long way to go in terms of changing people's habits in hotels. For China's hotel industry, it must work harder to create green hotels in order to better connect with the international market. Pay attention to the rational use of disposable goods, save natural resources, reduce operating costs, so as to enhance market competitiveness. Only in this way can we attract more customers and unify the environmental, economic and social benefits of hotels.

\section{References}

1. Lu Yao. Eliminate the six small pieces of travel more environmentally friendly. Zhejiang Daily,2015-0818(003).

2. Sha Lin,Shi Xiaoliang,Ji Yanjie. Research on the control of low-cost consumable items in hotels. Green Technology,2019(06):216-219.

3. Yang Qingzhen. The situation of supporting the use of disposable hygiene products in star hotels and management countermeasures. China Primary Health Care,2004(01):72

4. Li Qi. Research on the current situation of hotel disposables. China Trade,2009(05):116-117.

5. Yan Ying, He Jia, Niu Ruanxia. Research on the use of disposable products in hotels. Oriental Enterprise Culture,2013(23):84

6. National Tourism Administration of the People's Republic of China. Green tourism hotel standard interpretation. Beijing: China Tourism Publishing House, 2017.

7. $\mathrm{Gu}$ Jinjun. See how South Korea phased out disposables. Economic Daily,2013-02-27(009).M. Ben Rabha, M.F. Boujmil, M. Saadoun, B. Bessaïs, Eur. Phys. J. Appl. Phys. (to be published) 